\title{
A importância do conhecimento escolar em propostas curriculares alternativas*
}

\author{
The importance of school knowledge \\ for alternative curricular proposals
}

\author{
Antonio Flavio Barbosa Moreira**
}

\begin{abstract}
Resumo
0 artigo focaliza um processo de construção curricular em uma escola da rede municipal de Belo Horizonte, no qual vigora a proposta oficial da ESCOLA PLURAL. Destaca as dificuldades vividas pelo corpo docente da escola e desenvolve o argumento de que propostas curriculares inovadoras podem criar um espaço discursivo no qual se segregam as crianças das camadas populares, reduzindo suas possibilidades de autonomia na sociedade. Com base nas concepções de política de Stephen Ball e Jenny Ozga, analisamse os textos políticos da Escola Plural e de uma escola da rede municipal. Verificou-se a complexa relação entre documentos oficiais e experiências locais, bem como a necessidade de se afirmar a importância do conhecimento escolar no currículo. Argumentase que a supervalorização do aluno e de suas experiências culturais, em associação com a secundarização do conhecimento escolar, pode criar um espaço em que a criança seja confinada e jamais vista como normal.
\end{abstract}

Palavras-Chave: Proposta Curricular; Conhecimento Escolar; Política Educacional

\section{Abstract}

The paper focuses on a process of curriculum construction which was developed in a school from the Belo Horizonte educational system. The school is organized according to the official curricular proposal entitled PLURAL SCHOOL. It emphasizes the difficulties which were faced by the academic staff of the school and argues that innovative curricular proposals may create a space in which children from working class are segregated and have their possibilities of autonomy in society reduced. Drawing on the conceptions of politics by Stephen Ball and Jenny Ozga, the political texts, written on the level of the Plural School proposal and on the level of the school, are analyzed. The complex relations

* Texto derivado das pesquisas "Multiculturalismo e o campo do currículo no Brasil" e "Currículo, identidade e diferença: embates na escola e na formação docente", financiadas pelo CNPq.

** Doutor em Educação pela Universidade de Londres. Professor Titular da UCP e Professor Visitante da UERJ. Rio de Janeiro (Brasil). afmcju@infolink.com.br. 
among official documents and local experiences are emphasized. The importance of school knowledge is stressed. It is argued that the overvaluation of the students and their cultural experiences and the undervaluation of school knowledge can create a space in which children are confined and never considered as normal.

Keywords: Curricular Proposal; School Knowledge; Educational Politics

\section{INTRODUÇÃO}

Em investigação finalizada há poucos anos, ${ }^{1}$ focalizei propostas curriculares dos municípios do Rio de Janeiro e de Belo Horizonte, analisando também entrevistas com professores responsáveis pela formulação das mesmas. As propostas foram escolhidas por sua ênfase na cultura, por virem sobrevivendo há três gestões nas prefeituras (fato raro no país), bem como pelo caráter inovador que as distingue.

Nos discursos das propostas evidencia-se claramente a preocupação com a pluralidade cultural de nossa sociedade, com a necessidade de uma educação multiculturalmente orientada, com a urgência de se construir uma escola pública fundamental democrática e inclusiva. Em consonância com os propósitos enunciados, recomendam-se mudanças nos conteúdos, nos procedimentos pedagógicos, nas modalidades de avaliação, na gestão, no espaço e no tempo escolar.

Em recente texto sobre as duas propostas municipais (Moreira; Carvalho; Câmara, 2003), sugeriu-se que os sistemas de raciocínio pedagógico que norteiam seus discursos podem, em contraposição aos objetivos previstos, produzir uma dualidade que contribua para "confinar" e desqualificar crianças dos setores populares para a ação e a participação na sociedade, fazendo desses sistemas instrumentos de regulação da diversidade cultural. Foram levantadas hipóteses referentes a essa perspectiva, tendo em vista a forma como a avaliação e a organização do tempo escolar por ciclos são tratadas nos documentos.

Neste artigo, retomo o argumento de que propostas e estratégias curriculares inovadoras podem, paradoxalmente, criar um espaço discursivo no qual se "segregam" as crianças das camadas populares, reduzindo suas possibilidades de autonomia na sociedade, frente às

1 Trata-se da pesquisa "Multiculturalismo e o campo do currículo no Brasil", finalizada em 2002. 
crianças dos grupos privilegiados (Popkewitz, 1998). Procuro ilustrá-lo, então, recorrendo ao modo como o conhecimento escolar é abordado, tanto em textos da Proposta Curricular Escola Plural, ainda em vigor na rede municipal de Belo Horizonte, quanto em textos (escritos e orais) de uma escola da rede, à qual atribuo o nome fictício de Escola Vila Rica (EVR). Essa instituição escolar, reconhecidamente comprometida com a Proposta, procura organizar seu currículo conforme os princípios nela expressos. Analiso documentos formulados na escola e aproveito as contribuições decorrentes do fato de ter acompanhado, durante cerca de um ano, o trabalho de construção curricular nela desenvolvido.

Estruturo o artigo da seguinte forma: inicio com pontos de partida teóricos que me nortearam na abordagem dos textos políticos. A seguir, destaco, brevemente, aspectos marcantes da Proposta da Escola Plural. Volto-me, então, para a EVR. Após descrevê-la sucintamente, examino documentos elaborados durante o processo de construção curricular promovido por seus profissionais, recorrendo, também, para ilustrar meus pontos de vista, a depoimentos desses profissionais. Sem pretender estabelecer generalizações com base na experiência singular da EVR, finalizo o texto com considerações sobre a leitura de textos políticos e com reflexões sobre a necessidade de se redimensionarem o peso e o tratamento dados ao conhecimento escolar no currículo.

\section{SObre política e textos políticos}

Adoto a concepção de política de Stephen Ball (1997). A seu ver, qualquer teoria de política educacional precisa considerar seriamente a perspectiva de controle do Estado, sem a ela se limitar. Se as políticas são conjuntos de tecnologias e práticas que se desenrolam, em meio a lutas, em cenários locais, não faz sentido se ficar restrito às deliberações oficiais. Política é tanto texto como ação, tanto palavras como feitos, é tanto o que é intencionado como o que é realizado. As políticas serão sempre incompletas se não forem relacionadas à "profusão selvagem da prática local”. As políticas são cruas e simples. As práticas são sofisticadas, contingentes, complexas e instáveis.

As políticas desdobram-se em meio a situações de dominação, resistência e caos/liberdade. É preciso, contudo, superar e ampliar a dualidade dominação/resistência. Muitas práticas ocorrem fora dos limites do binário dominação/resistência, ocupando um terceiro espaço, 
conformado por preocupações, demandas, pressões, propósitos e desejos nem sempre convergentes.

Todavia, a despeito das diferentes leituras que os textos políticos podem suscitar, as interpretações não se elaboram em circunstâncias escolhidas pelos sujeitos. A ação é limitada, embora não determinada, pela política. Os ajustes implicados nas tentativas de resolver problemas emergentes apresentam aspectos criativos, inventivos e, ao mesmo tempo, confusos, contraditórios, capazes de inibir ou anular algumas das ações efetuadas. Há, portanto, restrições e possibilidades a serem consideradas, tanto na operacionalização como na análise de políticas.

Ball considera, ainda, que é preciso compreender como o conjunto de textos políticos pode exercer poder por meio da produção de verdades e conhecimentos como discursos. Discurso, nesse caso, é visto na perspectiva foucaultiana: os discursos constituem os objetos de que falam, procurando, simultaneamente, ocultar o modo como tais constituições ocorreram. Discursos referem-se ao que pode ser dito, pensado e feito. Discursos referem-se a quem pode falar, onde, quando, como e com que autoridade. Discursos configuram itinerários para o pensamento e, portanto, exercem autoridade.

Daí a necessidade de se levarem em conta, no estudo de políticas, tanto leituras, traduções e mudanças quanto limites e constrangimentos. Ou seja, a interpretação e a operacionalização de políticas necessariamente referem-se a disputas, que se travam em uma moldura discursiva cambiante, o que articula e restringe o pensar e o atuar.

Em minha análise, procuro acrescentar à visão de política como texto e como discurso, sugerida por Ball, a concepção de texto político adotada por Jenny Ozga (2000). Para a autora, os textos políticos contêm narrativas particulares: contam uma história sobre o que é tido como possível ou desejável de ser conseguido por meio de políticas educacionais. Pode-se lê-los como se lê qualquer outro tipo de narrativa. Pode-se examiná-los tomando por base personagens e ação, pode-se focalizar o uso de estruturas da língua que visem provocar certas impressões e respostas, pode-se analisar sua "voz" autoral ou os múltiplos pontos de vista que supostamente abrigue.

Pode-se, de outra perspectiva, vê-los como úteis recursos de análise, em termos das mensagens que transmitem ou procuram transmitir sobre a fonte da política (interesses a que serve), o âmbito da política (como se 
concebem e abordam as questões), bem como o padrão da política (como se modificam as relações e que mudanças são requeridas para isso).

Ainda com base em Ozga (2000), podem-se considerar como textos políticos tanto os mais formais, como leis, decretos, pareceres, documentos, extratos, quanto quaisquer outros materiais que possam ser vistos como significativos no conjunto dos parâmetros discursivos de uma investigação. Ou seja, Ozga opta por não oferecer uma base clara para a seleção dos textos. Ao contrário, flexibiliza de tal forma a categoria que abre espaço para interpretações imaginativas, inspiradas nos estudos de historiadores e analistas culturais, nas quais se pode transcender o caráter formal comum nas análises políticas. Amparado em Ozga, incluo, no âmbito dos textos políticos, tanto materiais elaborados por profissionais da educação da EVR quanto falas dos mesmos em reuniões, encontros e seminários organizados pela escola.

No exame dos textos políticos da Escola Plural e da EVR, busco identificar interesses a serem atendidos, concepções e abordagens escolhidas, novas relações e mudanças demandadas, preferencialmente no que se refere a conhecimento escolar. Apóio-me também em Ball, no esforço por compreender ajustes e limites envolvidos na operacionalização da proposta oficial na instituição em pauta.

\section{Sobre o discurso instaurador da Escola Plural}

A Escola Plural é bastante conhecida pelos pesquisadores do campo da educação e deve ser vista como uma possibilidade de nosso tempo. Assim, cabe analisá-la levando em conta o contexto político, social e educacional das três últimas décadas, bem como sua concretização como proposta de governo.

O movimento de renovação pedagógica que se desencadeou no país desde o final dos anos 1970 possibilitou uma série de mudanças nas redes de ensino; entre as quais a de Belo Horizonte pode ser vista como pioneira. O esforço por construir uma escola pública de qualidade sempre esteve presente no ideário da democratização da educação mineira. Esse esforço intensificou-se a partir da década de 1980, inspirando o Congresso Mineiro de Educação e Congresso Político-Pedagógico da Rede Municipal de Ensino de Belo Horizonte, assim como norteando as lutas por autonomia nas escolas, por eleição de diretores, por gestão democrática, por fortalecimento dos colegiados e dos conselhos de classe, por 
reformulações curriculares, pela criação do ciclo básico de alfabetização, pela revitalização das escolas normais, pela construção coletiva de projetos político-pedagógicos, por diversificação de atividades, por novas formas de organizar espaço e tempo, pela capacitação permanente de profissionais, por novos procedimentos de avaliação (BH/SMED, 1994; Castro, 2000; Souza, 2000).

Essas significativas expressões do movimento de renovação pedagógica originaram uma nova concepção de escola, mais voltada para questões de cultura, diferença, identidade, classe social, raça e gênero, o que abriu espaço para a Escola Plural, apresentada em fins de 1994 pela Secretaria Municipal de Educação e implantada em 1995. Ou seja, a Escola Plural completou, em 2005, dez anos de idade.

A que interesses parece servir a proposta? Sem desejar oferecer um receituário, a proposta afirma ter por objetivo "subsidiar as discussões, ser uma referência” (BH/SMED, 1995a, p. 5). Pretende ser útil para que se enfrente o fracasso escolar dos setores populares e melhor se intervenha nas estruturas excludentes do sistema escolar e na cultura que as legitima. Os interesses são, portanto, os das crianças das camadas populares, para as quais se busca construir uma escola mais democrática e inclusiva. Para essas crianças, quer-se resgatar a escola "como espaço de formação bumana, rompendo com a concepção da mesma como espaço apenas de instrução" (BH/SMED, 1995b, p. 6, grifos no original).

Acrescentam-se aos interesses dos alunos que têm sido reprovados e que acabam por abandonar a escola os interesses dos docentes, orgulhosos "diante da rica pluralidade de ações emergentes" (BH/SMED, 1994, p. 2), cuja direção se quer captar, para que, ao devolvê-la às escolas, se forme um coletivo de professores, convencidos e comprometidos, sensíveis às novas tendências pedagógicas e aos avanços dos direitos sociais. A idéia é que tais profissionais se engajem na elaboração e na operacionalização de um "novo ordenamento para a Educação Básica da Rede Municipal, que seja mais democrático e igualitário que o atual" (BH/SMED, 1994, p. 5). A intenção parece ser a produção de um discurso que de fato construa o objeto sobre o qual versa, construindo-se possibilidades para o pensamento e a ação dos professores. O convite vai-se tornando cada vez mais irresistível: o que se tem é uma proposta que se apresenta como oriunda da prática docente e não dos cérebros de membros iluminados de uma comissão de especialistas. O governo incorpora e oficializa o que se fazia e que até então se via como transgressor 
e ilegítimo. Assume-se a escola emergente no discurso, instigando-se sua efetivação e seu aperfeiçoamento na prática. A política como arte de sedução faz-se presente.

Que questões são focalizadas nos Cadernos publicados (que sugerem referências e buscam estabelecer elos entre a SMED e as escolas, bem como entre as próprias escolas da rede)? Como essas questões são abordadas? Que novas relações se propõem? Que mudanças são previstas? Como se trata o conhecimento escolar? $\mathrm{Na}$ tentativa de responder a tais perguntas, opto por debruçar-me sobre os primeiros documentos oficiais, que focalizam os eixos norteadores da proposta, os conteúdos e processos de formação plural, a reorganização dos tempos escolares e a nova lógica da avaliação.

Nos eixos norteadores, afirma-se a necessidade de uma intervenção coletiva mais radical, para que se venha a redefinir a escola como espaço e tempo de vivência dos direitos de todos à "realização plena como sujeitos socioculturais" (BH/SMED, 1994, p. 5). Destaca-se a "sensibilidade perante a realização do ser humano como sujeito cultural" (BH/SMED, 1994, p. 6). Insiste-se em que se recupere, nas salas de aula e nas disciplinas do currículo, a função escolar de espaço público privilegiado de cultura. Quer-se uma escola articulada com a produção cultural da cidade, multiplicando seus tempos culturais, abrindo os currículos às dimensões culturais que os transpassam. Assim, "a totalidade da experiência escolar passa a ser cultural” (BH/SMED, 1994, p. 6).

Salienta-se, também, a experiência de produção coletiva na escola, comentando-se que já se faz visível uma nova cultura de construção do cotidiano da escola, que certamente precisa ser incrementada. As escolas, acrescenta-se, somente serão educativas quando "se constituírem como centros de formação coletiva. É nessa tarefa que elas adquirem sua identidade e sua autonomia mais plena" (BH/SMED, 1994, p. 6).

Mudanças significativas parecem ser necessárias, tendo em mente as virtualidades educativas da materialidade da escola. Há, então, que se repensar aspectos físicos e condições de trabalho. Há que se reorganizar tempo, espaços, processos, trabalho pedagógico, grades, seriações, horários, hierarquias. Há que se mudar a escola. O reconhecimento dessa necessidade mostra "O avanço da consciência dos profissionais" (BH/SMED, 1994, p. 7), capazes de perceber que a experiência escolar não pode ser reduzida a uma relação interpessoal entre educadores e educandos. O discurso acentua o que as práticas já evidenciam e ajuda a construir novas práticas em que novos sujeitos, norteados por novas verdades, irão desenvolver. 
A responsabilidade se divide, portanto, entre uma proposta de governo que reflita as tendências em curso e os profissionais que irão operacionalizá-la.

Novas condições se evidenciam para a Escola Plural. É preciso que a vivência de cada idade de formação se dê sem interrupção. A visão da escola como "preparo para um outro momento" deve ser abandonada em favor da escola como um tempo presente, como um tempo de vivência, cuja finalidade encontra-se em si mesmo, não no futuro. Uma nova concepção de infância, como tempo de formação, de cidadania, de vivência social e de vivência de direitos hoje precisa difundir-se.

Outra mudança a ser implantada na escola refere-se aos ciclos de formação, introduzidos em outro eixo norteador - a socialização adequada a cada idade-ciclo de formação. Rejeita-se a lógica das precedências, dos pré-requisitos, do vencimento de etapas de domínios e habilidades, bem como a lógica norteadora das avaliações classificatórias e reprovatórias, sugerindo-se que o tempo da escola corresponda a um tempo de socialização-formação no convívio entre sujeitos na mesma idade-ciclo de formação-socialização. Rejeita-se, assim, a organização do tempo escolar por séries, buscando-se substituí-la por uma organização por ciclos de formação, configurados pela faixa etária dos educandos (infância, préadolescência e adolescência), que passam a eixo vertebrador da nova estrutura.

Reafirma-se o caráter democrático da proposta da Escola Plural, inspirada nas variadas experiências ocorridas na rede de ensino nos últimos anos. São os organizadores dessas iniciativas - os profissionais da educação - os que têm construído a nova escola, construindo-se, no processo, como "um novo profissional, com nova identidade, novos valores, novos saberes e habilidades" (BH/SMED, 1994, p. 8). Continuase, com intensidade, a seduzir os profissionais da rede a aderir à proposta e a tecer um discurso que vai estabelecendo, suavemente, novos conhecimentos, novas verdades, novos limites para a ação docente.

A proposta de cada ciclo deve abranger a aquisição de conteúdos curriculares, bem como de suas dimensões formadoras, ou seja, deve visar à socialização de vivências e experiências, valores, representações, identidades de gênero, raça, classe etc. Além disso, os conteúdos devem ser trabalhados de forma significativa, e nesse sentido, recomenda-se a articulação entre as disciplinas curriculares e os temas contemporâneos, insistindo-se mesmo na abordagem dos conhecimentos por meio dos projetos. Como os 
conhecimentos não estão prontos não representam verdades absolutas, considera-se que mais importante do que reproduzi-los é "aprender a aprender e aprender a viver" (BH /SMED, 1994, p. 17). Daí a ênfase nos projetos, que possibilitam a "construção do conhecimento significativo de forma globalizada e relacional” (BH/SMED, 1995a, p. 38).

Essas perspectivas justificam também a inserção de temas transversais no currículo, que favorecem o relacionamento das disciplinas com a realidade contemporânea, dotando-as de valor social. O novo desenho curricular pretende "a formação de sujeitos capazes de construir, de forma autônoma, seus sistemas de valores e, a partir deles, atuarem criticamente na realidade que os cerca" (BH/SMED, 1994, p. 19-20). Em última análise, concebidos os conteúdos como instrumentos para a formação dos alunos e para a compreensão do mundo em que vivem, há que se superar o caráter fragmentado com que usualmente são tratados nas grades curriculares.

Mudados os conteúdos e o tempo escolar, há que se modificar a avaliação, que passa a ser diagnóstica e formativa, com o objetivo de não só respeitar as diferenças socioculturais e de ritmos de aprendizagem dos educandos, como também de auxiliar o professor a identificar avanços e dificuldades no processo ensino-aprendizagem. A avaliação perde seu caráter classificatório e passa a ser "entendida como fonte principal de informação e referência para a formulação de práticas educativas que levem à formação global de todos os indivíduos" (BH/SMED, 1996, p. 7).

Em resumo, o eixo da Escola Plural é o aluno, devendo a construção curricular nortear-se por seus interesses. Para isso, cabe acolher as manifestações culturais dos setores populares, selecionar conteúdos significativos e úteis, trabalhar com estratégias (como o método de projetos) que favoreçam a integração desses conteúdos, reorganizar o espaço e o tempo na escola, agrupar os alunos por idade, modificar o sentido e os procedimentos da avaliação. Refletindo tendências já vividas pelos docentes, a Escola Plural apresenta-se como um discurso que as incorpora, estimula e pretende materializá-las nas salas de aula, com a participação desses docentes, para garantir a inclusão e a formação plena das crianças que vêm sistematicamente fracassando em seu processo de escolarização.

Quase dez anos após a publicação dos primeiros Cadernos, reiteramse propósitos e evidenciam-se novas ênfases. 


\section{Sobre o discurso mais recente sobre a Escola Plural}

Documento recente (BH/SMED, 2003) salienta a função da escola como tempo/espaço de formação de crianças, jovens e adultos. A intenção é favorecer a construção de um currículo que promova a inclusão e garanta aos alunos o acesso e permanência com qualidade na escola, a partir das necessidades, experiências e vivências próprias de cada fase do desenvolvimento humano.

Reafirma o ponto de vista de que "os processos escolares são diversificados, conforme a comunidade escolar, de acordo com as condições dos educandos e as condições de trabalho na escola, por isso propõe referenciais curriculares que orientem a construção da proposta curricular em todos os níveis e modalidades de ensino" (BH/SMED, 2003, p. 7), em função da rejeição de um currículo único e obrigatório, "remetemo-nos à própria realidade da escola, ao diagnóstico e respostas aos problemas existentes" (BH/SMED, 2003, p. 7). O documento destaca propostas que têm dado certo, "porque elas existem e é com elas que temos percebido as possibilidades de aprendermos e elaborarmos melhor as respostas que as dificuldades têm demandado" (BH/SMED, 2003, p. 7). Aos interesses de docentes e discentes somam-se, agora, mais visíveis, os interesses da escola.

Segundo o documento, os professores têm demandado um aprofundamento da proposta curricular da Escola Plural, que melhor caracterize o que é próprio de cada ciclo de idade de formação de cada nível e modalidade de ensino e permita a construção de uma proposta curricular centrada no interior da escola, responsável por pensar e produzir seu currículo, "onde o profissional se forma e forma, ensinando e aprendendo a conviver e a aprender" (BH/SMED, 2003, p. 8, grifos no original).

O propósito do novo documento é, então, "subsidiar a discussão curricular das escolas que oferecem a Educação Básica e a modalidade de Educação de Jovens e Adultos. São textos para serem lidos, discutidos e modificados" (BH/SMED, 2003, p. 9). Os textos referem-se a cada um dos ciclos que compõem a Educação Fundamental, a alunos do $2^{\circ}$ e do $3^{\circ}$ ciclos que ainda estão em processo inicial de construção do conhecimento escolar, assim como à Educação de Jovens e Adultos.

O documento ressalta a necessidade de "refletirmos mais sobre o desenvolvimento infantil e a forma de trabalharmos com estas crianças" (BH/SMED, 2003, p. 13). Insiste na necessidade de se conhecerem os 
sujeitos com os quais se vai trabalhar. Quando a escola caracteriza seu público, fica mais fácil delimitar quais são as demandas por ele apresentadas e como contemplá-las. Listam-se competências e processos pedagógicos a viabilizar (que devem possibilitar o desenvolvimento das diversas dimensões formadoras dos alunos). Os conteúdos das disciplinas continuam a ser vistos "como instrumentos culturais, necessários para que os alunos avancem na sua formação global e não como fim em si mesmo" (BH/SMED, 2003, p. 28).

Buscando fornecer diretrizes mais precisas para o trabalho docente, o documento caracteriza-se por um teor mais prescritivo que os anteriores e por iluminar mais intensamente a dimensão psicológica do desenvolvimento da criança e do adolescente. Será o foco no aluno e em seu desenvolvimento que poderá propiciar as condições indispensáveis às mudanças desejadas no currículo. Entretanto, ao oferecer subsídios para a seleção dos elementos curriculares, confunde e mistura competências, estratégias e conteúdos, tornando-se, a meu ver, pouco útil para os propósitos que busca alcançar. No documento se expressa, com clareza, a tensão (comum em muitas políticas curriculares) entre centrar o currículo na escola (estimulando a autonomia de seus profissionais) e subsidiar significativamente o processo de sua construção (facilitando a necessária tomada de decisões). Em síntese, o propósito de regular o processo de aquisição de conhecimentos e competências desejáveis mostra-se evidente no documento.

Abordo, a seguir, uma complexa e instigante leitura dos princípios da Escola Plural no espaço escolar.

\section{Sobre a Escola Vila Rica (EVR)}

A escola, cujo trabalho acompanhei por algum tempo e à qual atribuí o nome fictício de Vila Rica, está situada na região do Barreiro, área eminentemente de origem operária, próxima a grandes indústrias. Essa região configura-se como lugar onde se travaram inúmeras lutas operárias e onde se desencadearam movimentos por melhores condições de vida e trabalho, especialmente nos anos 1970 e 1980 (Almeida, 2005).

A comunidade de um dos bairros que compõem o Barreiro reivindicou o projeto da escola junto ao Orçamento Participativo e conseguiu que o prédio fosse construído. A escola veio, assim, satisfazer uma demanda da comunidade. Com duas semanas de reunião do corpo 
docente, as matrículas foram feitas e o trabalho se iniciou. Para analisar aspectos desse trabalho, baseio-me em textos políticos que incluem documentos elaborados pela Secretaria de Educação sobre a escola, documentos elaborados pela própria escola e falas dos educadores da escola. Recorro, ainda, a observações e registros pessoais. ${ }^{2}$

A escola começou a funcionar em 2000, de forma provisória, em prédio alugado, tendo, a partir de 2002, passado a funcionar no prédio em que hoje se encontra. Ela é rodeada por um muro, junto ao qual há um espaço gramado. Nos corredores há vasos de arbustos e azaléias. Placas indicam o acesso às salas de aula, à biblioteca (que comporta a sala de vídeo e uma sala para informática), ao gabinete da direção, à sala de professores, ao laboratório, à quadra de esportes, à cantina. Há um espaço destinado às atividades de Artes. Há também uma sala denominada multiuso, onde se realizam encontros, seminários e outras atividades que demandam espaço e movimentação. A escola é clara, espaçosa, funcional, muito bem cuidada e preservada (Almeida, 2005). Na Secretaria de Educação, é vista como uma das "tetéias" da rede municipal.

Funciona em três turnos. No diurno atende a turmas dos três ciclos e no noturno a turmas de Educação de Jovens e Adultos. O dinamismo e o entusiasmo da diretora e do corpo docente são evidentes. Grande parte dos professores trabalha em dois turnos e a equipe é majoritariamente feminina. O grupo é bem qualificado: em 2003, dos 18 docentes, 15 eram graduados em diferentes licenciaturas, dois estavam finalizando seu curso e um havia trancado a matrícula. Parcialmente escolhidos pela diretora por sua vez indicada pela Secretaria -, quando da inauguração da escola, são competentes e comprometidos com o projeto da Escola Plural. "Somos um grupo que, na sua maioria, caminha junto já há nove anos. Um grupo que privilegia o trabalho coletivo e que traz, na sua experiência, a perspectiva de implementar uma escola mais inclusiva." (Documento da SMED/BH referente à EVR, 2003)

Recebendo dominantemente crianças dos setores populares, a escola tem crescido e foi ampliando, gradualmente, os ciclos de formação com que trabalha. Desde os primeiros momentos, a equipe de educadores estabeleceu como meta o desenvolvimento do processo de construção

2 Para evitar a identificação da escola, optamos por não pontuar com clareza os documentos a ela referentes e por não incluí-los nas Referências Bibliográficas. 
curricular. A discussão se iniciou em torno dos temas que marcam o debate educacional contemporâneo (conteúdos, competências, estratégias pedagógicas, projetos, atividades significativas, avaliação), confirmando o quanto o discurso da Escola Plural contribui para estabelecer contornos para análises, reflexões e práticas.

O grupo de professores definiu uma organização curricular (para o diurno) estruturada em torno de quatro eixos: a) Leitura e Escrita; b) Linguagem Matemática; c) Natureza, Sociedade, Cultura e Ética; d) Arte e Estética. Preservou-se o enfoque disciplinar em Português e Matemática e incluíram-se as outras áreas do conhecimento nos projetos. Ainda que questionável, a estratégia revela como, a despeito dos limites criados para o pensamento e a ação pelas políticas, os sujeitos envolvidos nas situações concretas e nos problemas locais que os desafiam acabam por traduzir e modificar essas políticas.

Para melhor levar a cabo a tarefa de construir o currículo, os professores formaram grupos de estudo (Leitura e Escrita, Matemática, Projetos), que se reuniam semanalmente em horários definidos na carga horária docente, para aprofundamento em: Matemática; Leitura e Escrita; Projeto; Artes. Os grupos se constituíam de docentes com formação acadêmica diferenciada, pois a intenção era promover um diálogo entre as áreas e favorecer a integração curricular (Documento da SMED/BH referente à EVR, 2003). Apesar da valorização dos grupos de estudos, aceitos por todos os professores, foi-me feita a seguinte observação: "Será que não corremos o risco de fragmentar nosso trabalho?". Ao mesmo tempo, outro professor questionava: "Como aproveitar melhor os saberes dos colegas? Até que ponto é legal um professor sem habilidades para o ensino de uma disciplina trabalhar com ela?’. As tensões entre uma abordagem especializada e um enfoque mais integrador ilustram-se com clareza nas divergentes falas selecionadas.

As discussões, leituras e reflexões dos docentes foram registradas, elaborando-se então quatro Cadernos, publicados em 2002: a) Primeiro Encontro - Escola: que lugar é esse?; b) Segundo Encontro - Aprender: o que isso significa?; c) Terceiro Encontro - Aprender o quê?; d) Quarto Encontro - Avaliação. Muitas das idéias apresentadas nos Cadernos incluem-se em documento posterior, composto pelo Projeto Político Pedagógico da Escola, pelos projetos desenvolvidos e pela avaliação do trabalho realizado em 2002. Tanto nos documentos quanto nas falas dos docentes, em seminários e reuniões, expressaram-se os interesses a que a 
escola procurava atender, os temas abordados, as condições e as mudanças vistas como necessárias para a concretização do projeto políticopedagógico.

São os interesses das crianças das camadas populares os que se deseja acolher na EVR. No Primeiro Caderno, destaca-se que as classes populares conquistaram o direito de entrar na escola. No entanto, como ela tende a privilegiar linguagem e tarefas associadas aos "filhos dos ricos", acaba por "espirrar" crianças. "Como as outras crianças e adolescentes poderiam se sentir incluídas se tudo na escola era tão diferente da vida deles?", pergunta-se no Caderno. "Os filhos das classes populares conquistaram o acesso a essa escola, mas não conseguiram que essa mesma escola os enxergasse como sujeitos que também constroem conhecimentos. Como, às vezes, acontece até hoje...". Conclui-se então: "Dessa forma, outras mudanças precisam ser feitas".

Que mudanças permitirão que a Escola Plural, consubstanciada na EVR, possa acatar os interesses das crianças que vêm sendo "espirradas" das salas de aula? Mudanças na gestão da escola, na organização do tempo do aluno e do professor, na concepção de aprendizagem, no currículo, nos conteúdos, nas estratégias, na avaliação. Daí a forte preocupação com o conhecimento da comunidade em que a escola se insere, com os projetos de trabalho, com atividades significativas, com os registros dos trabalhos e das reflexões desenvolvidas. Daí o intenso foco no aluno - sujeito da aprendizagem. Uma das professoras realçou: "Avançamos na concepção de educação com eixo central no sujeito, na aprendizagem do aluno. $\mathrm{O}$ grupo hoje compreende o processo do aprender a ler e a escrever. Em relação à aquisição de leitura e escrita houve um salto. Conseguimos entender como o aluno pensa".

Conforme um dos documentos:

A visão de aprendizagem vem mudando... Aprender é como tecer uma rede: as linhas se entrelaçam e se encontram em vários pontos. Em cada ponto - cruzamento de linhas diferentes novos conhecimentos são estabelecidos, novos saberes construídos, e a rede vai aumentando, porque aprendemos mais a cada dia que passa.

Aprendemos quando relacionamos o que já temos construído dentro de nós com o que aparece de novo. Relacionamos as coisas umas com as outras. Não existe aprendizagem a partir do nada. Nesse sentido, somos um pouco parecidos com a terra. A semente 
não brota no chão árido e pedregoso, sem água e sais minerais. Nós também quando aprendemos é porque somos solo fértil que acolhe a nova informação e lhe dá novo significado (Projeto Político Pedagógico da EVR, 2002, p. 11).

Quanto ao tempo escolar, a EVR segue as orientações oficiais, organizando-se por ciclos de idade, que visam garantir mais tempo para o aprendizado dos alunos na construção de conceitos, valores etc. Em cada ciclo procura-se respeitar a organização dos grupos por idade, facilitandose as trocas socializantes e a construção de auto-imagens e identidades mais equilibradas. No entanto, em função de dificuldades sentidas no processo de alfabetizar crianças e, posteriormente, de ensinar Matemática para grupos heterogêneos, a escola decidiu romper a lógica da enturmação por idade e, três vezes por semana, durante uma hora, forma grupos de alunos com base no nível de adiantamento. Esse procedimento de trabalho corresponde ao "Projeto Intervenção", que "consiste no reagrupamento das crianças possibilitando intervenções apropriadas" (Anexo ao Projeto Político Pedagógico da EVR, p. 28). Assim, para resolver problemas emergentes, a EVR efetua leitura flexível e criativa dos documentos da Escola Plural.

Quanto à reestruturação e melhor aproveitamento do tempo docente, há três professores para cada duas turmas, que se organizam em função dos projetos e se distribuem pelos grupos de estudos. O tempo destinado a projeto é usado pelo professor para preparação de atividades a serem desenvolvidas nos projetos individuais da sua turma, para reuniões com um grupo, às quartas-feiras (em que acontecem trocas de experiências), e, ainda, para reuniões pedagógicas às sextas-feiras (destinadas a projetos coletivos visando à formação em serviço). São, em resumo, doze horas para regência, seis horas para projeto e duas horas para reuniões. Mas, segundo uma das professoras, "sentimos falta de um coordenador pedagógico e precisamos de mais professores". Condições ainda melhores de trabalho parecem ser vistas como necessárias para as mudanças pretendidas.

A visão de currículo adotada na Escola passa "pela formação ampla do ser humano levando em consideração as suas diferenças individuais, sua bagagem cultural, os conteúdos necessários à sua formação e todas as mudanças pelas quais o mundo vem passando" (Projeto Político Pedagógico da EVR, p. 10). A escola é vista como um "dos espaços responsáveis pelo desenvolvimento das potencialidades humanas, envolvendo as várias dimensões do ser humano" (Idem). 
O foco na formação do aluno, presente nos documentos da Escola Plural, repete-se nos documentos da escola. É ele o eixo norteador das atividades. "Nos preocupamos em conhecer nossos alunos e tratamos o conhecimento de maneira dinâmica e significativa, ou seja, relacionando-o com a vida e com os outros conhecimentos. São muitos os conhecimentos acumulados pela humanidade, historicamente construídos e pedagogicamente organizados em disciplinas escolares." (Projeto Político Pedagógico da EVR, p. 12-13) Os conteúdos disciplinares "devem ser trabalhados de forma interativa, interdisciplinar e contextualizada" (Ibidem, p. 13).

Os projetos ocupam lugar de destaque no trabalho realizado pela Escola, chegando mesmo a constituir quase uma outra "disciplina". Segundo uma das professoras, "as outras áreas do conhecimento [que não Português e Matemática] estariam aqui. Os alunos optam por um dado projeto por mais ou menos dois meses." No diurno, os projetos desenvolvidos são: Ecolovida, Giroletras e Identidade. No noturno, Identidade, Ecolovida e Trabalho.

Em um dos documentos, afirma-se que "nos projetos valorizamos os conhecimentos do educando, trazemos novas informações para que ele se perceba como sujeito, parte integrante da natureza e da sociedade tornando-se um agente consciente, crítico e multiplicador". Por meio dos projetos, busca-se partir das experiências do aluno para ampliar seus conhecimentos, permitir que ele ouça as experiências dos colegas, as confronte entre si e as confronte com os saberes escolares. $O$ foco continua a ser o aluno - suas necessidades, suas experiências e seus interesses.

Espera-se que os projetos de trabalho e as atividades significativas possibilitem um enfoque globalizador do processo de ensino/ aprendizagem. Assim, novas aprendizagens ganham sentido e significado para o estudante. "Temos hoje a consciência de que em nossa escola trabalhamos ora com atividades significativas, ora com projetos." (Projeto Político Pedagógico da EVR, 2002, p. 20)

Nos Cadernos e no Projeto Político Pedagógico encontram-se informações sobre os projetos. Com o Projeto Identidade pretende-se que o aluno vá construindo sua identidade de maneira integrada, abrangendo as diferentes dimensões do conhecimento: social, afetiva, psicológica, física, estética, ética e cognitiva. "É importante, além de trabalhar a identidade individual da criança, construir a identidade da sala. Atividades como desenho tipo auto-retrato e desenho da turma podem contribuir." (Ibidem, p. 36) Leituras e traduções complexas (talvez mesmo 
contraditórias) mostram-se como formas de, no espaço escolar, materializar as intenções expressas nos documentos oficiais.

O Projeto Giroletras procura facilitar a comunicação da criança com o mundo, por meio de questões presentes no inconsciente infantil: "é o aflorar dos sonhos, desejos, medos e fantasias" (Projeto Político Pedagógico da EVR, p. 30). A intenção é aprimorar habilidades que favorecem o seu crescimento, propiciando o gosto pela leitura, a crítica literária e o intercâmbio entre os leitores.

No Projeto Ecolovida parte-se do pressuposto que agir ecologicamente é imprescindível para resguardar a vida no planeta. Objetiva-se, então, a formação de uma consciência ecológica, de uma postura individual e coletiva frente ao outro e ao meio ambiente.

No Projeto Corpo e Movimento organizam-se brincadeiras que proporcionam à criança momentos lúdicos de interação, descontração e relaxamento. Quer-se possibilitar "a tomada de consciência corporal e espacial, cumprimento de regras e respeito aos combinados do grupo, além de propiciar o despertar das emoções, da sensibilidade e da criatividade" (Ibidem, p. 31).

Por fim, com base no Projeto Sexta Cultural abre-se espaço para que os alunos apresentem, como desejarem, assuntos trabalhados na semana e/ou nomes, nos projetos coletivos e/ou específicos da turma. A criança tem a chance de expressar-se por meio de desenho, pintura, música, dança, teatro.

De certo modo, os dois últimos projetos asseguram a presença das disciplinas Artes e Educação Física no currículo, reivindicação clara de seus docentes. Em um dos encontros, a professora de Artes indagou de modo muito incisivo se a Arte deve estar contemplada no currículo, com um tempo próprio, ou deve atravessar os outros conteúdos. Perguntou: "Qual o papel da Arte na educação? Como entra no currículo? Entra via projeto ou como uma disciplina? É preciso pensar também no sujeito professor. $\mathrm{Na}$ organização da escola não há horário específico de Artes. Matemática tem aula específica. Artes não. Por quê?”. A meu ver, mais do que no sujeito professor, a docente sugere que se pense em um lugar mais apropriado para sua disciplina, inferiorizada, segundo ela, na hierarquia dos saberes escolares.

No Relatório do Grupo de Estudo de Projetos afirma-se a existência, na escola, de diferentes entendimentos a respeito do tema em questão. A 
leitura de um texto sobre projetos e as discussões subseqüentes possibilitaram a identificação de sensível lacuna no currículo: "O grande nó para o trabalho com projetos: definir os conceitos das áreas de conhecimento [...] a serem desenvolvidos em cada ciclo". O Relatório apresentou perguntas levantadas durante os encontros do grupo. Destaco: Não estamos utilizando, de fato, os projetos para alfabetizar? Como favorecer a aprendizagem tendo em mente a diversidade cognoscitiva dos alunos? Tendo percebido discriminação racial entre as crianças, não caberia incluirmos a questão no currículo? No mesmo Relatório incluíram-se também propostas: a continuidade dos grupos de estudo e a socialização de seus processos, assim como a organização desses grupos com base nas áreas de conhecimento do Projeto Político Pedagógico.

Respostas, reações e adaptações subvertem e/ou aperfeiçoam o que o discurso dos documentos oficiais constrói. As brechas são ampliadas, as dificuldades percebidas e enfrentadas, por vezes crítica e criativamente, por vezes apressada e contraditoriamente. As dúvidas se explicitam e novas formas de pensar a organização do currículo se misturam às mais tradicionais, configurando uma mescla pouco usual, porém formulada, experimentada e modificada ativamente pelos docentes. Reações às determinações da Secretaria de Educação (e mesmo aos propósitos da diretora) se fazem sentir, desestabilizando-se crenças, princípios e estratégias antes aceitas. O currículo oficial se refaz, se enriquece, se subverte. Ou seja, as operacionalizações jamais se fazem simples e linearmente; decorrendo, sim, de decisões sofridas, coletivamente tomadas, e de corajosas tentativas de alteração da prática pedagógica, ainda que nem sempre bem-sucedidas.

A complexidade do diálogo que a escola trava com a proposta oficial se faz notar. Como assinala Bakhtin (2004), o diálogo constitui um caso particularmente evidente e ostensivo de contextos diversamente orientados. "Os contextos não estão simplesmente justapostos, como se fossem indiferentes uns aos outros; encontram-se numa situação de interação e de conflito tenso e ininterrupto.” (Ibidem, p. 107)

A tensão implicada no trabalho com projetos, derivada das demandas envolvidas no desenvolvimento de uma perspectiva globalizante e, ao mesmo tempo, nos indispensáveis esforços por ordenação e sistematização os conhecimentos, expressou-se em diversos momentos de minhas idas à escola. Em uma das reuniões, uma professora afirmou: "O projeto acaba sendo uma camisa-de-força, pois acaba tudo sendo projeto e a escola gira 
em torno disso. Os projetos acabam sendo institucionais, com os mesmos conteúdos. Há necessidade de clarear os conteúdos das disciplinas e investir mais neles." Outro docente perguntou: "Como ampliar o conhecimento do aluno? Os conhecimentos ficam vagos. Eles estão mais claros em Português e Matemática que não são trabalhados como projetos. Temos que definir os conceitos de cada área a serem desenvolvidos em cada ciclo."

Outra professora, participante do Projeto Ecolovida, comentou: "Me senti perdida. Não conseguia saber o que os alunos já tinham de conhecimentos anteriores. Como trabalhar sem saber isso? Somente no final a coisa melhorou. Só há um mês, partindo da queimadura de um aluno, consegui sistematizar um pouco." Ainda outra acrescentou: "O projeto Ecolovida visava trabalhar a consciência ecológica. A idéia era falar sobre animais, o homem neles inserido, a água. Mas não ficavam claros, de fato, os conceitos que estavam sendo trabalhados. Um projeto não deve ter início, meio e fim? Não parte de alguma pergunta, de um problema? Não tem produto? Acho que não sabemos de fato o que é projeto."

A diretora da escola, no entanto, defende o trabalho por ela valorizado e alerta: "Se você enxerta conteúdos no projeto, que não se refiram ao projeto, você mata o projeto. $\mathrm{O}$ trabalho de projeto tem que ser prazeroso, tem que ter motivação."

Em reunião na Secretaria de Educação, sistematizaram-se algumas das dúvidas dos docentes da escola: como trabalhar conteúdos e conceitos de forma significativa? Como dosar os conteúdos dentro dos ciclos? Como garantir a formação integral do aluno sem perder de vista os conteúdos? Como avançar na prática pedagógica dos projetos? Como garantir a construção do conhecimento trabalhando com projetos? Que conceitos escolher? Como lidar com turmas heterogêneas? Como dividir os alunos por turmas?

Em decorrência de conquistas, incertezas e ajustes em todo o processo de construção curricular, os grupos de estudo se organizaram, a partir de 2004, da seguinte forma: Grupo de Ciências, Grupo de História, Grupo de Geografia, Grupo de Artes/Educação Física. Os grupos estudaram os Parâmetros Curriculares Nacionais (PCN) dessas áreas, confrontando-os com os projetos. Os Cadernos da Escola Plural foram revisitados, mas avaliados como pouco úteis para a definição dos conteúdos por ciclo. "O medo de prescrever acaba levando à frouxidão", comentou uma docente. 
Em encontro da equipe de docentes, em 2004, a questão da seleção dos conteúdos permanecia candente, como se verifica nas falas que se seguem, de diferentes docentes: "Pensamos na escola como o único lugar em que se aprende. Isso é preocupante. A dinâmica da escola é lenta. Ela não consegue concorrer com a televisão." Outro professor replica: "Mas a mídia é diferente do que valorizamos. Cabe à escola instrumentalizar e sistematizar." Outro ainda pergunta: "Como selecionar conteúdos importantes?". Diferentes respostas se ouvem: "Seria mais importante uma metodologia de acesso ao conhecimento." "Levar em conta a criança." "É preciso que o conhecimento seja útil para estabelecer relações." "Estabelecer relações entre o conhecimento e o aluno." "Que é problema para o aluno? Às vezes o interesse não é tão imediato." "Estabelecer relações entre os conteúdos." "Relações com a sociedade." "Ler o mundo amplamente." "Em História precisamos ensinar o que são permanência e mudança. Que fatos são importantes para esses conceitos?" "Que conteúdos são essenciais? O especialista e o livro didático podem ajudar a esclarecer." "O especialista também tem dúvidas. O especialista não dá conta." "Não sabemos definir aquilo que o aluno não pode deixar de saber. Não podemos trabalhar de forma vaga.".

Em abril de 2004, a EVR organizou um seminário em que os grupos de estudo, com base nas discussões travadas nos encontros, apresentaram sugestões, reflexões e dúvidas referentes às concepções, às noções e aos conceitos a serem trabalhados em Matemática, Português, História, Geografia, Ciências, Educação Física e Artes. Os representantes de Artes e de Educação Física, ao mesmo tempo em que reafirmaram as especificidades de suas áreas, propuseram-se a um diálogo com as demais, sem a elas se submeterem.

Um mês depois, a diretora afirmou que o seminário levantou uma série de demandas que ainda não haviam sido suficientemente digeridas. Mas acrescentou: "Ficou claro para o grupo que a EVR não trabalhava com projetos, ainda que trabalhasse bem." Os projetos da escola eram mais projetos institucionais, mais efetivos para trabalhar ações que conhecimentos. Uma professora destacou o quanto o seminário instigou a continuidade das discussões, acentuando o quanto se havia avançado, principalmente no diurno. Outra valorizou a mobilização dos docentes, que apreciam poder tomar decisões de forma autônoma e participar da construção coletiva do currículo.

Os projetos continuaram em cena, mas as perguntas se modificaram. "Que vamos trabalhar de História, Geografia e Ciências nos projetos?" 
"O que da cultura vamos considerar?" A diretora já se mostra menos desconfiada em relação às disciplinas, afirmando não ver problemas em trabalhar com disciplinas e com projetos. "O importante é não deixar de dar conta dos conteúdos relevantes." Outra professora comenta: "Há necessidade de discussão coletiva para decidirmos que conhecimentos seriam fundamentais."

No início de dezembro de 2004, novo seminário reuniu docentes e membros da Secretaria de Educação. Mais uma vez os grupos apresentaram os avanços conseguidos e, para cada área (Português; Matemática; Arte, Estética e Educação Física; Ciências, Geografia e História), discutiram: relevância, perspectivas, ações pedagógicas, conteúdos a serem aprendidos. Na Educação de Jovens e Adultos, os docentes definiram temas geradores, passíveis de favorecer "o diálogo entre os conhecimentos historicamente construídos e os desafios do mundo atual”. São eles: ecologia, identidade, trabalho. Promovem-se também aulas coletivas, vistas como atividades que mobilizam professores e estudantes em torno de um tema. A metodologia prevista é a pedagogia de projetos. O coletivo de professores planeja inicialmente o trabalho, que se vai enriquecendo com a intervenção de estudantes e outras pessoas interessadas. Fecha-se o ciclo de cada aula com uma avaliação oral ou escrita que busca sintetizar os conhecimentos estudados.

A importância dos conteúdos parece ter sido resgatada. As discussões travadas mostraram-se mais ousadas, mais ricas. O medo dos conteúdos foi perdido. A vara, curvada demais para o lado do aluno e das estratégias, retomou um equilíbrio (instável e provisório, certamente).

\section{Considerações Finais}

O exame de textos políticos da Escola Plural e da EVR suscitoume reflexões sobre a complexa relação entre documentos oficiais e experiências locais, assim como sobre a necessidade de se repensar a importância e a abordagem do conhecimento escolar no currículo.

Há que se destacar a complexidade do processo curricular vivido pelos competentes e comprometidos sujeitos da EVR. As atividades realizadas configuraram uma delicada teia em que movimentos divergentes, criativos, cuidadosos, avançaram e retrocederam, em meio a disputas e negociações, em uma trama local na qual o oficial jamais se materializou de forma linear. 
O que se viveu na escola foi um denso processo de significação e ressignificação de textos, um processo sem fim, no qual cada leitura se fez com base em sentidos já dados. Como afirma Stuart Hall (2003, p. 363), "Se você tem de dizer algo novo, é porque o processo está transformando os significados que já estão lá. Portanto, cada ato de significação transforma o estado efetivo de todas as significações já existentes."

A despeito do empenho da Secretaria de Educação em promover uma "leitura preferencial" de seus documentos, os textos escapam de suas mãos, são lidos de uma outra forma. Em consonância com os pontos de vista de Stephen Ball e de Stuart Hall, não vale acreditar, todavia, que toda e qualquer leitura seja possível. Afinal, sempre se procura controlar as formas de significar o mundo.

Qual o resultado desse imprevisível processo de negociação? Nem uma leitura transparente dos documentos, nem o pleno exercício da resistência e da autonomia. Sustenta Hall (2003, p. 371): "Prefiro algo entre esses dois extremos. Então, eu simplesmente falo do código negociado." Acrescenta o autor: "A maioria de nós nunca está completamente dentro de uma leitura preferencial ou totalmente a contrapelo do texto. Nós sempre lutamos e remamos contra a maré dele." (2003, p. 371)

Nesse sentido, cabe entender os esforços desenvolvidos na EVR como leituras negociadas - "provavelmente o que a maioria de nós faz, na maior parte do tempo" (Ibidem, p. 371). Leituras negociadas que versaram, dominantemente, sobre os sentidos dos conteúdos e dos procedimentos curriculares. No processo, driblaram-se algumas das leituras preferenciais sugeridas pela Secretaria, evidenciando-se que "o elemento de fechamento jamais funciona, o que não significa que não esteja presente" (Ibidem, p. 372).

Volto-me, então, para o alvo central das discussões travadas na EVR - o conhecimento escolar -, objeto de minha atenção em recentes artigos (Moreira, 2004/2005). Apoiando-me em Muller (2003), tenho procurado argumentar que, no processo de construção curricular, os focos na criança e na cultura, ainda que indispensáveis, são insuficientes. Insisto no sentido de que a eles se associe uma aguda preocupação com o conhecimento, com sua aquisição, com uma instrução ativa e efetiva, com um professor ativo e efetivo, que bem conheça, escolha, organize e ensine os conteúdos de sua disciplina ou área do conhecimento. 
Não basta abrir a escola a diversas manifestações culturais, não basta ampliar os tempos culturais no currículo. Não basta uma escola aberta aos saberes e às experiências dos estudantes e da comunidade em que se insere. Não basta conceber e tratar o aluno, que vem sendo excluído da escola e da participação na sociedade, como um ser cultural. Não basta procurar desenvolver no aluno uma auto-imagem positiva. Não basta organizar-lhe um espaço para convivência, socialização e aprendizado de valores e condutas. Não basta a sensibilidade com a totalidade da formação humana. Não basta clamar pelo direito de todos os estudantes à realização plena como sujeitos socioculturais. Se tudo isso é indispensável, não é suficiente.

Há que se voltar a considerar mais rigorosamente os processos de selecionar, organizar e sistematizar os conhecimentos a serem ensinados e aprendidos na escola. Talvez valesse a pena pensar no que Muller (2003) denomina de "coerência conceitual", que estimula a promover, na sala de aula, uma evolução coerente da aprendizagem de conceitos. O autor insiste: É preciso considerar o "conhecimento como conhecimento", não apenas como instrumento para a formação, para a conscientização, para a promoção do indivíduo.

Ou seja, o conhecimento não pode ser tido, simplesmente, como meio para tornar o ser humano mais humano. Pode ser útil levar em conta a recomendação de Dewey no sentido de que a ênfase no desenvolvimento não implique um currículo apenas centrado no aluno ou em atividades, no qual se negligenciam a seleção e a organização de conteúdos de fato relevantes. Cabe acrescentar que relevância, nesse caso, precisa incluir tanto a preocupação com conteúdos significativos, que levem em conta interesses e necessidades do aluno, como a preocupação com a seqüência de conteúdos, necessária a uma apreensão lógica e ordenada dos mesmos. Faz-se necessário, então, um certo cuidado para que não se ignore a chamada "lógica das disciplinas" em prol do foco no desenvolvimento integral do educando em uma realidade plural.

Os significados e os padrões culturais do cotidiano não são suficientes para garantir o aprendizado do aluno e ampliar seus horizontes. Precisamos, além da imersão nos padrões do cotidiano, da imersão nos padrões da disciplina escolar. Para isso, há absoluta necessidade de um professor capaz de uma instrução explícita, planejada e efetiva. Há necessidade de um professor que, além de bem conhecer o aluno e a comunidade da escola, conheça os conceitos a serem dominados e seja bem sucedido ao orientar o aluno na consecução das metas definidas. $\mathrm{O}$ 
foco do processo se dispersa, assim, entre aluno, cultura, professor e conhecimento.

Em outras palavras, não há como abrir mão de bons professores, capazes de bem selecionar procedimentos e conteúdos. Associo ao ponto de vista que estou defendendo o alerta de Bauman (1998), referente às possibilidades de emancipação na contemporaneidade. Para ele, na modernidade, a busca (nunca totalmente bem-sucedida) por constituir a ordem implicava neutralizar os poderes intermediários das comunidades e das tradições. A intenção era "desencaixar" os indivíduos, fazendo-os livres para escolherem a vida que lhes apetecesse viver. A intenção era desafogar o indivíduo do peso de uma identidade herdada. A identidade convertia-se em uma realização própria, em uma tarefa individual, de responsabilidade do indivíduo.

$\mathrm{Na}$ contemporaneidade, quando incerteza, insegurança, fragilidade, descompromisso, provisoriedade, individualismo, consumismo, discriminação, violência, desigualdade e desesperança compõem o cenário em que se vive, pensar em emancipação, em autonomia, demanda que se retome e complete a tarefa de "desencaixe" da modernidade (Bauman, 1998). Concordando com essa perspectiva, argumento que se pode favorecê-la, no currículo, evitando-se a formação de guetos, evitando-se ficar restrito aos artefatos culturais familiares ao aluno, evitando-se passar da essencialização de padrões hegemônicos para a celebração de padrões minoritários. Para se garantir ao aluno o direito de escolher sua identidade, faz-se necessário impedir que o Estado ou a "tribo" acabe por dele retirar tanto essa liberdade de escolha quanto essa responsabilidade. Para isso, contudo, há que se criar oportunidades de acesso às ciências, às artes, a novos saberes, a novas linguagens, a novas interações, a outras lógicas, à capacidade de buscar conhecimentos, ao aprofundamento, à sistematização e ao rigor. Há que se considerar o aluno em suas diferentes dimensões sem que, no entanto, se coloquem em plano secundário o intelecto e a aprendizagem. Em última análise, sustento que a revalorização do conhecimento escolar no currículo pode constituir útil instrumento para o resgate da tarefa de "desencaixe" ansiada por Bauman.

Lanço ainda mão dos pontos de vista de Popkewitz (1998) para argumentar a favor do conhecimento escolar. Em propostas curriculares que visem fortalecer o poder dos alunos das camadas populares pode-se criar, com base nos conhecimentos pedagógicos empregados, um espaço de "confinamento" nos quais esses alunos sejam sempre os "outros", os 
"diferentes", os "impuros", os "estranhos". Obviamente, os resultados tenderão a ser opostos aos esperados.

Em outras palavras, os conhecimentos pedagógicos norteadores das decisões curriculares podem inscrever certa seletividade no modo como os docentes pensam, sentem e falam sobre os estudantes. Podem orientar seus discursos no sentido de classificar a criança, construindo-se um espaço em que a criança jamais pode ser uma criança "padrão", "normal". O que estou acentuando é que esses conhecimentos são produtivos, capazes de qualificar determinados estudantes e desqualificar outros para a cidadania.

Sugiro que a supervalorização do aluno e do desenvolvimento, que venho encontrando no discurso de propostas curriculares oficiais alternativas, e a conseqüente secundarização do conhecimento escolar (restrito a instrumento para a formação plena do estudante) pode ajudar a criar um "compartimento" no qual esse estudante, que tanto se deseja promover, seja situado e visto sempre como "diferente", incapaz de apreender conteúdos formais das disciplinas científicas, possivelmente úteis à tarefa do "desencaixe" a ser retomada na contemporaneidade. Acredito, ao mesmo tempo, que leituras críticas, criativas, negociadas dos textos oficiais, podem talvez desestabilizar os conhecimentos pedagógicos que têm norteado nossas escolhas. Podem talvez estimular novas formas de pensar e de agir na construção de uma escola mais justa e eqüitativa.

\section{Referências Bibliográficas}

ALMEIDA, C. L. Da igualdade de direitos ao direito à diferença: interfaces no cotidiano de uma escola plural. Dissertação (Mestrado) - Universidade Federal de Uberlândia, Uberlândia, 2005.

BAKHTIN, M. Marxismo e filosofia da linguagem. São Paulo: Hucitec, 2004.

BALL, S. Education reform: a critical and post-structural approach. Buckingham: Open University Press, 1997.

BAUMAN, Z. O mal-estar da pós-modernidade. Rio de Janeiro: Jorge Zahar, 1998.

BELO HORIZONTE. Secretaria Municipal de Educação. Proposta políticopedagógica. Escola Plural, Caderno 0. Belo Horizonte: Secretaria Municipal de Educação, 1994.

BELO HORIZONTE. Secretaria Municipal de Educação. Construindo uma referência curricular para a escola plural: uma reflexão preliminar. Escola Plural, Caderno 1. Belo Horizonte: Secretaria Municipal de Educação, 1995a. 
BELO HORIZONTE. Secretaria Municipal de Educação. Proposta curricular da Escola Plural: referências norteadoras. Escola Plural, Caderno 2. Belo Horizonte: Secretaria Municipal de Educação, 1995b.

BELO HORIZONTE. Secretaria Municipal de Educação. Avaliação dos processos formadores dos educandos. Escola Plural, Caderno 4. Belo Horizonte: Secretaria Municipal de Educação, 1996.

BELO HORIZONTE. Secretaria Municipal de Educação. Referenciais curriculares. Escola Plural, Educação Básica. Belo Horizonte: Secretaria Municipal de Educação, 2003.

CASTRO, E. V. Movimentos educacionais em Minas precursores da Escola Plural. In: DALBEN, A. I. L. F. (Org.). Singular ou Plural? Eis a escola em questão! Belo Horizonte: GAME / FAE / UFMG, 2000.

HALL, S. Da diáspora: identidades e mediações culturais. Belo Horizonte: Editora UFMG, 2003.

MOREIRA, A. F. B. Currículo, diferença cultural e diálogo. Educação e Sociedade, 79, p. 15-38, 2002.

MOREIRA, A. F. B. Articulando desenvolvimento, conhecimento escolar e cultura: um desafio para o currículo. Cadernos de Educação, 22, p. 55-74, 2004.

MOREIRA, A. F. B. O estranho em nossas escolas: desafio para o que se ensina e o que se aprende. In: GARCIA, R. L.; ZACCUR, E.; GIAMBIAGI, I. (Org.). Cotidiano - diálogos sobre diálogos. Rio de Janeiro: DP\&A, 2005.

MOREIRA, Antonio Flavio B.; CARVALHO, Merise S.; CÂMARA, Michelle J. A diversidade cultural nas propostas Multieducação e Escola Plural. In: II SEMINÁRIO INTERNACIONAL DE EDUCAÇÃO INTERCULTURAL, GÊNERO E MOVIMENTOS SOCIAIS. Anais... Florianópolis: UFSC, 2003. MULLER, J. Revisitando o progressivismo: Ethos, política, pathos. In: GARCIA, R. L.; MOREIRA, A. F. B. (Org.). Currículo na contemporaneidade: incertezas e desafios. São Paulo: Cortez, 2003.

OZGA, J. Investigação sobre politicas educacionais: terreno de contestação. Porto: Porto Editora, 2000.

POPKEWITZ, T. Struggling for the soul: the politics of schooling and the construction of the teacher. New York: Teachers College Press, 1998.

SOUZA, M. G. Educação e diversidade cultural: uma análise da proposta da Escola Plural do Município de Belo Horizonte, MG. Dissertação (Mestrado) - PUC-RJ, Rio de Janeiro, 2000.

Recebido em: 01/01/2006

Aprovado em: 15/03/2007 